\title{
Estimation in vivo of the body and carcass chemical composition of growing lambs by real-time ultrasonography ${ }^{1}$
}

\author{
S. R. Silva ${ }^{2}$, M. J. Gomes, A. Dias-da-Silva, L. F. Gil, and J. M. T. Azevedo \\ CECAV-Universidade de Trás-os-Montes e Alto Douro, Department of Animal Science, \\ 5000-911 Vila Real, Portugal
}

\begin{abstract}
The relationship between ultrasound measurements and empty body and carcass chemical composition was investigated. A $500-\mathrm{V}$ real-time ultrasound with a 7.5-MHz probe combined with image analysis was used to make in vivo measurements to predict the empty body and carcass chemical composition of 31 female lambs of two genotypes, ranging in BW from 18.2 to $48.9 \mathrm{~kg}$. Eleven ultrasound measurements of s.c. fat, muscle, and tissue depth were taken at four different sites (over the 13th thoracic vertebra, between the 3rd and 4th lumbar vertebrae, at the 3rd sternebra of the sternum, and over the 11 th rib, $16 \mathrm{~cm}$ from the dorsal midline). The single best predictor of empty body fat quantity and energy value was the s.c. fat depth over the 13th thoracic vertebra $\left(\mathrm{r}^{2}=0.904\right.$ and 0.912 ; $P<0.01$, respectively). Body weight was used with ultrasound measurements in multiple regression equa-
\end{abstract}

tions to establish the best independent variables combination for predicting chemical composition. Results showed that BW and two of the three ultrasound measurements (s.c. fat depth over the 13th thoracic vertebra, between the 3rd and 4th lumbar vertebrae, and tissue depth over the 11th rib, $16 \mathrm{~cm}$ from the dorsal midline), explained 94.7 to $98.7 \%(P<0.01)$ of the quantity of water and fat and the energy value variation in the empty body and carcass. Body weight per se was the best predictor of the quantity of protein, accounting for 97.5 and $96.8 \%(P<0.01)$ of the variation observed in the empty body and carcass, respectively. The results of this study suggest that BW and some ultrasound measurements combined with image analysis, particularly subcutaneous fat depth over the 13th thoracic vertebra, allow accurate prediction of empty body and carcass chemical composition in lambs.

Key Words: Body Composition, Lambs, Real-Time Ultrasound

(C2005 American Society of Animal Science. All rights reserved.

J. Anim. Sci. 2005. 83:350-357

\section{Introduction}

Accurate measurements of changes in body composition and the energy content of live animals are key to understanding the response to the intake of nutrients. Classically, measurements have been done by direct or indirect calorimetry, comparative slaughter, or dilution techniques (McDonald et al., 2002). However, the development of reliable, noninvasive, and easily performed techniques in live animals, measuring traits with strong correlations to body composition are alternatives that should be encouraged. These techniques may also be used for other purposes, such as breeding, estimation of carcass composition before slaughter, reproductive

\footnotetext{
${ }^{1}$ This work received financial support from the FCT-Project SAPIENS-POCTI/1999/CVT/36259, which we gratefully acknowledge.

${ }^{2}$ Correspondence: Apt 1013 (fax: 351 259350482; e-mail: ssilva@ utad.pt).

Received April 6, 2004.

Accepted October 28, 2004.
}

physiology, and to support on-farm nutritional decisions (Wilson, 1992; Moeller, 2002).

Computer tomography and magnetic resonance imaging are techniques that can successfully achieve these objectives. However, the initial price, operating costs, and lack of mobility of the equipment severely limit their utilization in animal science (Lawrence and Fowler, 2002).

Ultrasound techniques are alternatives that have been used in recent decades, mainly on live animals, for classification of carcasses, particularly in the swine industry (Moeller, 2002). Only a few studies dealing with ultrasound prediction of chemical composition and energy value of carcasses (Leymaster et al., 1985; Ramsey et al., 1991) or empty body (Wright and Russel, 1984) have been performed. Recent advances in technology have made it possible to use real-time ultrasonography (RTU) for these purposes. This technology, associated with image analysis, offers the possibility of achieving a degree of precision similar to that achieved with computer tomography or magnetic resonance imaging in predicting body composition (Szabo et al., 1999). 
Table 1. Chemical composition and estimated energy and protein values of the experimental diets

\begin{tabular}{|c|c|c|}
\hline \multirow[b]{2}{*}{ Constituent } & \multicolumn{2}{|c|}{ Diets } \\
\hline & $\begin{array}{c}\text { Low } \\
\text { energy }\end{array}$ & $\begin{array}{l}\text { High } \\
\text { energy }\end{array}$ \\
\hline Chaffed hay, g/kg of DM & 747.0 & 314.0 \\
\hline Concentrate, $\mathrm{g} / \mathrm{kg}$ of $\mathrm{DM}$ & 253.0 & 686.0 \\
\hline \multicolumn{3}{|c|}{ Ingredient composition, $\mathrm{g} / \mathrm{kg}$ of concentrate DM } \\
\hline Ground corn & 192.0 & 320.0 \\
\hline Soybean hulls & 187.8 & 313.0 \\
\hline Soybean meal & 567.0 & 278.5 \\
\hline Protected fat (Megalac) $)^{\mathrm{a}}$ & 17.5 & 29.0 \\
\hline $\mathrm{NaCl}$ & 2.3 & 3.9 \\
\hline Premix & 1.2 & 2.0 \\
\hline Calcium carbonate & 8.2 & 13.6 \\
\hline Bentonite & 24.0 & 40.0 \\
\hline \multicolumn{3}{|c|}{ Diet chemical composition, \% of DM } \\
\hline $\mathrm{OM}$ & 93.2 & 89.6 \\
\hline $\mathrm{NDF}$ & 56.2 & 37.7 \\
\hline $\mathrm{CP}$ & 13.2 & 17.0 \\
\hline $\mathrm{ME}, \mathrm{MJ} / \mathrm{kg}$ of $\mathrm{DM}^{\mathrm{b}}$ & 8.7 & 10.8 \\
\hline ERDP:FME ${ }^{c}$ & 9.7 & 9.9 \\
\hline
\end{tabular}

${ }^{a}$ Volac, Int., Ltd., Hertfordshire, U.K.

${ }^{\mathrm{b}}$ Calculated as $\mathrm{ME}=$ apparent $\mathrm{DE}$ (measured in digestion trials) $\times 0.82$ (Blaxter et al., 1966).

${ }^{\text {c}}$ Ratio of effective rumen degradable protein (ERDP), calculated from effective $\mathrm{CP}$ content of ingredients and $\mathrm{N}$ degradation parameters according to AFRC (1993) to fermentable ME (FME), calculated as $\mathrm{FME}=\mathrm{ME}-\mathrm{ME}_{\mathrm{fat}}(\mathrm{AFRC}, 1993)$.

To assess the possibility of predicting whole body and carcass chemical composition of growing sheep using RTU, data were recorded from an experiment designed to evaluate the efficiency of energy utilization of two diets offered to two different genotypes of lambs.

\section{Materials and Methods}

Source of Data

Data were obtained from an experiment performed by Gomes (2001). Briefly, a growth trial was carried out using 25 female lambs from each of the breeds: the Île de France and the native Portuguese breed, Churra da Terra Quente. Five lambs of each breed were slaughtered at the start of the experiment (initial slaughter group) when their BW was approximately $45 \%$ of their mature BW (45 and $76 \mathrm{~kg}$ for Churra da Terra Quente and Île de France, respectively). The remaining lambs of each breed were assigned randomly to one of two dietary treatments: low- and high-energy diets that were initially formulated to provide 9 and $11.5 \mathrm{MJ}$ of $\mathrm{ME} / \mathrm{kg}$ of DM, respectively. Diets were balanced for effective rumen degradable protein $(10 \mathrm{~g} / \mathrm{MJ}$ of fermentable $\mathrm{ME}$ ), according to the recommendations of AFRC (1993) for growth lambs. The actual composition, chemical analysis, and estimated energy and protein value of the diets are presented in Table 1.

Five lambs of each breed and dietary treatments were slaughtered when they reached $65 \%$ of their mature
BW. One Île de France lamb fed the high-energy diet in a parallel digestion trial was also slaughtered. Therefore, a total of 31 animals were slaughtered (10 animals from the initial slaughter group plus 21 animals slaughtered at $65 \%$ of mature BW). Before ultrasound measurements and subsequent slaughter, the animals were shorn, deprived of food for $24 \mathrm{~h}$, and weighed.

\section{Ultrasound Measurements}

Just before slaughter, animals were scanned with an Aloka SSD 500-V real-time scanner (Tokyo, Japan) using a 7.5-MHz linear probe (UST-5512U-7.5). The wool at each measurement point was clipped close to the skin and a gel was used as a coupling medium. The probes were placed perpendicular to the backbone over the 13th thoracic vertebra and between the 3rd and 4th lumbar vertebrae. The s.c. fat depth was measured over these points, with skin at the 13 th thoracic vertebra and between the 3rd and 4th lumbar vertebrae or without (SC13 and SC34, respectively). Muscle depth and total tissue depth were also measured at these anatomical points. The muscle depth value was recorded as the greatest depth of the longissimus thoracis et lumborum muscle, and total tissue depth was considered as the depth from skin to the deepest border of the LM (TD13 and TD34). The s.c. fat depth and the tissue depth were measured at the $3 \mathrm{rd}$ sternebra of the sternum. The total tissue depth was also obtained over the 11 th rib, $16 \mathrm{~cm}$ from the dorsal midline (TDtho).

\section{Image Analysis}

When a satisfactory image of the sites of measurement was obtained, it was captured on a video printer, digitized, and the measurements made by image analysis with National Institute of Health 1.57 software (http://rsb.info.nih.gov/nih-image/). All the scanning and interpretation was done by the same technician, who had considerable experience in ultrasound technology and interpretation of images and solid knowledge on the anatomy of species under study.

\section{Slaughter Procedure and Sample Collection}

After being stunned with a captive bolt gun, the animals were slaughtered by severing the carotid arteries. The blood was collected in a tray, and the esophagus was tied off. The fore and hind limbs (feet) were then separated at the radio-carpal and tarso-metatarsal articulations, respectively. The pelt, head, and all internal organs were removed and individually weighed. The alimentary tract was weighed full, and then emptied and reweighed. All noncarcass body components (subsequently referred to as offal) were then combined and stored in plastic bags at $-20^{\circ} \mathrm{C}$ until grinding. The carcass was stored at $4^{\circ} \mathrm{C}$ for $24 \mathrm{~h}$, reweighed, and then split down the vertebral column with a band saw, after which each side was weighed. The left half of the carcass was then stored in plastic bags at $-20^{\circ} \mathrm{C}$. 
Frozen carcasses and offal were cut into small pieces with an electric band saw and immediately ground in a mill (Retsch SM 200, Haan, Germany) with a sieve plate having holes $8 \mathrm{~mm}$ in diameter. The mixture was then ground through another sieve plate with 4-mm holes. Milled carcasses were homogenized in an industrial mixer (Stef; Rimini, Italy). Two random samples of approximately $300 \mathrm{~g}$ were obtained, placed in a sealed plastic box, and stored at $-20^{\circ} \mathrm{C}$ for later chemical analysis.

\section{Chemical Analyses}

Samples were analyzed in duplicate for moisture, ash, and $\mathrm{CP}(\mathrm{N} \times 6.25)$ according to AOAC (1990). Lipid analysis was performed by ether extraction in a Tecator Soxtec HT 1043 (Höganäs, Sweden) according to the procedure described by Tecator (ASTN, 1998). The energy value was determined by adiabatic bomb calorimetry (model 1241, Parr Instrument Co., Moline, IL).

\section{Calculations}

Weight loss during carcass storage was assumed to be a water loss. Carcass and offal composition $(\mathrm{kg})$ was calculated from the respective weights and chemical composition assuming that the left and right halves of the carcasses had similar compositions. Weights of the empty body chemical components were calculated as the sum of carcass and offal components.

\section{Statistical Analyses}

Data from all 31 female lambs (16 île de France and 15 Churra da Terra Quente) were used as one large group for statistical analysis. To assess the accuracy of empty body and carcass chemical composition estimated by RTU, coefficients of determination and residual standard deviation were calculated for single regression equations using the JMP-SAS statistical package (Version 5.01; SAS Inst., Inc., Cary, NC). Multiple regression analyses were performed (SAS Version 8.2) to determine which combinations of in vivo ultrasound measurements and BW best predicted empty body and carcass chemical composition and energy value. The best-fitting regression equations were evaluated by the coefficients of determination, residual standard deviation, and Mallow's statistic, which is used as a measure of bias (MacNeil, 1983).

\section{Results and Discussion}

\section{Ultrasound Measurements and Chemical Composition Data}

Table 2 shows that the lambs presented a large range of variation in BW and chemical composition. The range of variation in empty BW was 15.6 to 25.6 and 27.0 to $42.7 \mathrm{~kg}$ for Churra da Terra Quente and Île de France, respectively (data not shown). The corresponding val- ues for the carcasses were 8.5 to 15.7 and 17.2 to 28.8 $\mathrm{kg}$, respectively (data not shown).

The variation of the gross chemical constituents expressed as absolute amounts was high, particularly for fat. The energy value also varied greatly. This was expected because variation in chemical composition between the two genotypes at the same degree of maturity was also observed (Gomes, 2001). As animals reach maturity, the rate of fat retention increases, whereas that of protein decreases, and fat makes up most of the energy value. As expected, the CV of chemical constituents and energy value when expressed as proportions of BW were much lower because the conversion of these components to their proportions removes most of the variation caused by differences in weight (Dinkel et al., 1965).

The data of ultrasound measurements are also presented in Table 2 . The variation is also large, particularly for SC13 and SC34 and TDtho. Although the absolute values of s.c. fat measurements were low, the ultrasound equipment used was able to accurately measure these traits and therefore separate differences among animals. The image analysis, the skill and experience of the operator, and the $7.5-\mathrm{MHz}$ probe used were able to give good images, as is shown in Figure 1. Previous work has shown that improvement in the predicting ability of RTU can be achieved by using high-frequency probes, better image analysis, or different sites for measurements (McLaren et al., 1991; Young and Deaker, 1994; Williams, 2002).

\section{Estimates of Chemical Composition and Energy Value of Empty Body and Carcass from Ultrasound Measurements by Simple Regression}

The ratios between individual energy values of the empty body or carcass measured by bomb calorimetry and individual energy values calculated from compositional data were very close to the unity; they ranged from 0.997 to 1.01 (Gomes, 2001; data not shown). In making these calculations, the energy value of body protein and fat were assumed to be 23.6 and $39.3 \mathrm{MJ} /$ $\mathrm{kg}$, respectively, and $23.1 \mathrm{MJ} / \mathrm{kg}$ for OM free of fat.

The parameters of single linear relationships between fat, muscle, and total tissue depth measured in live animals as described above, and the gross chemical constituents and energy value of the empty body and carcass, are presented in Tables 3 and 4 . With one exception (TDtho, water in the empty body) all of the coefficients of determination were improved when predicting the absolute amounts of chemical constituents or energy value than when these variables were predicted as proportions of empty body (range of increase in $\mathrm{r}^{2}=0.024$ to 0.472 ) or carcass (range of increase in $\mathrm{r}^{2}=0.057$ to 0.497 ). As previously mentioned and discussed by Dinkel et al. (1965), statistically, absolute values were favored. Also, in the context of studies planned to measure responses in body chemical composition to nutrient intake, as was the case in the work 
Table 2. Summary of data used to develop regression equations

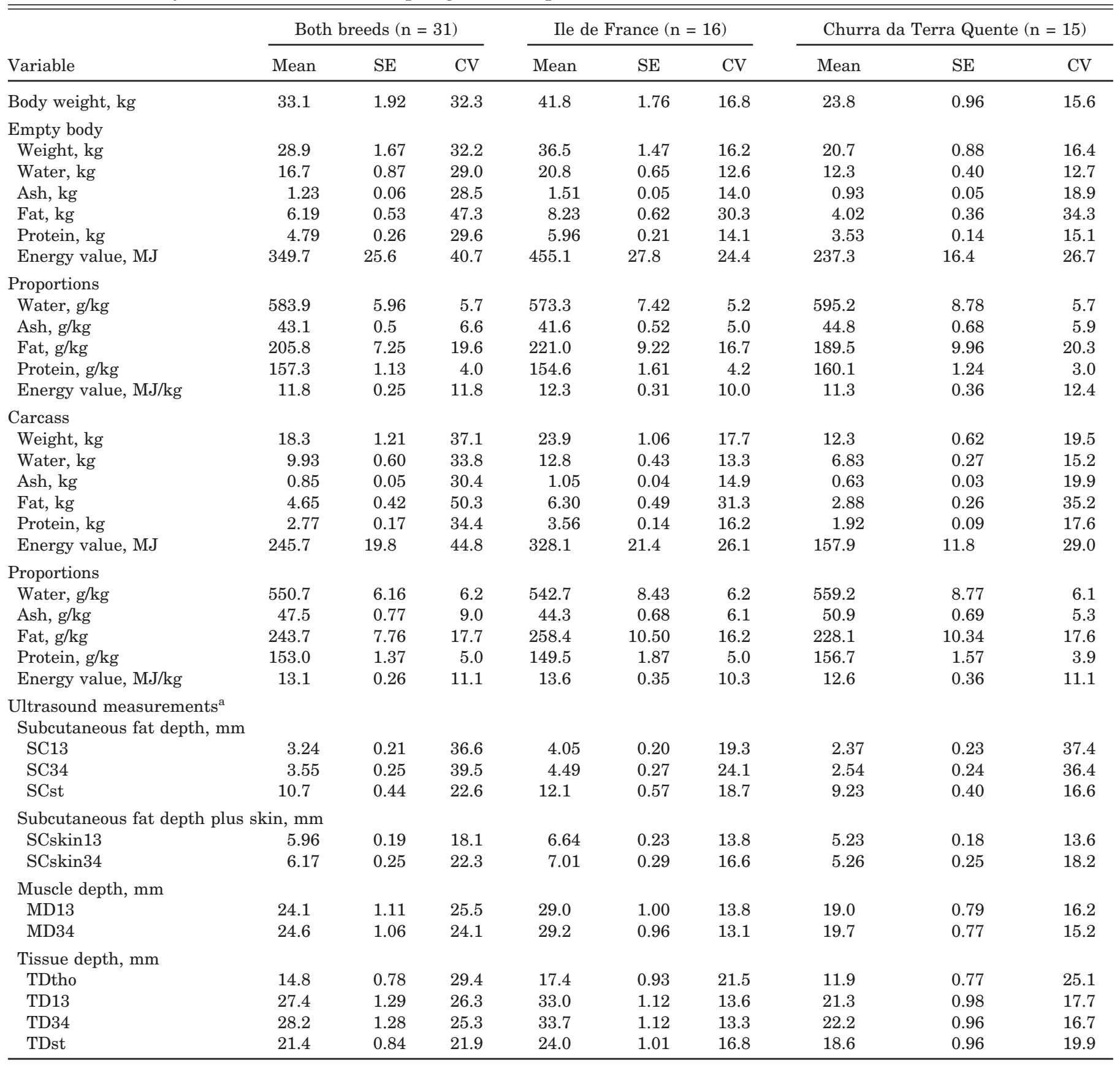

${ }^{a}$ Ultrasound measurements: SC13 = s.c. fat depth over the 13th thoracic vertebra; SC34 = s.c. fat depth between the 3rd and 4th lumbar vertebrae; SCst = s.c. fat depth at the 3rd sternebra of the breast bone; SCskin13 = s.c. fat depth over the 13th thoracic vertebra plus skin; SCskin34 = s.c. fat depth between the 3rd and 4th lumbar vertebrae plus skin; MD13= muscle depth over the 13th thoracic vertebra; MD34 = muscle depth between the 3rd and 4th lumbar vertebrae; TD13 = total tissue depth over the 13th thoracic vertebra; TD34 = total tissue depth between the 3rd and 4th lumbar vertebrae; TDst = total tissue depth at the 3rd sternebra of the breast bone; and TDtho = tissue depth over the 11 th rib $16 \mathrm{~cm}$ from the dorsal midline.

of Gomes (2001), total quantities also are more meaningful.

Using SC13 as single independent variable explained $90 \%$ or more of the total quantity of chemical fat or the energy value of the empty body or carcass (Tables 3 and 4). This suggests that, at least for the range of BW covered by the study, SC13 mirrored changes in noncarcass fat, particularly the internal fat deposits. In the case of the quantity of protein, TD13 accounted for the greatest proportion of the variance $\left(r^{2}=0.847\right.$ and 0.844 for the empty body and carcass, respectively). However, the SC13 measurement allowed us to predict the amount of protein both in the empty body and carcass $\left(\mathrm{r}^{2}=0.822\right.$ and 0.831 , respectively). Other authors have found in growing lambs that this measurement has potential as an estimator of carcass protein (Ramsey et al., 1991), the predictions often being better than those obtained from muscle depth (Chadwick et al., 


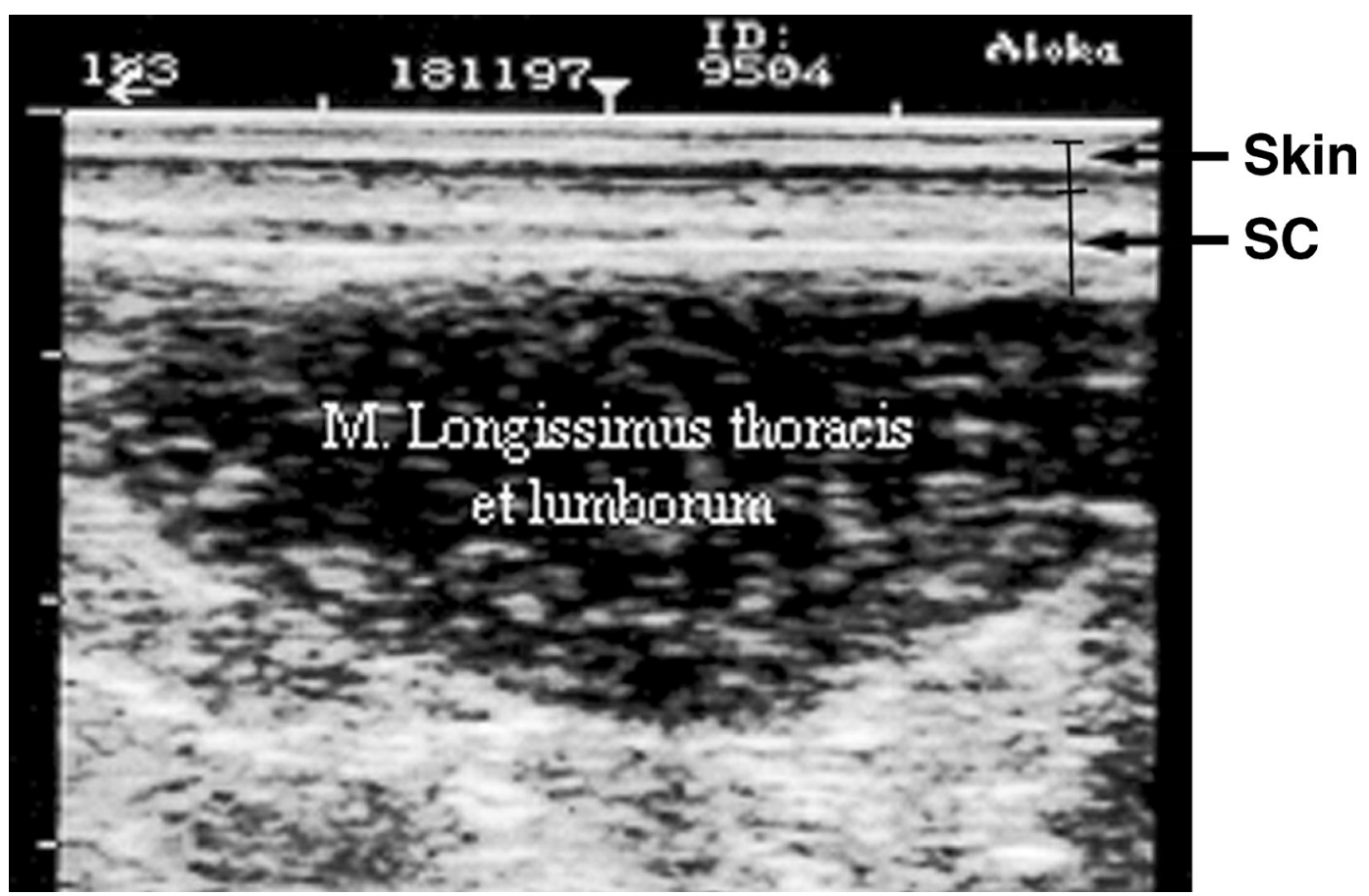

Figure 1. Ultrasonogram between the 3rd and 4th lumbar vertebrae showing skin, subcutaneous fat (SC), and longissimus thoracis et lumborum muscle.

1993). Whether the same is true when an animal reaches physiological maturity and fat deposition continues, while muscle mass accretion slows down, remains to be proved.

Ultrasound measurements at the 13 th thoracic vertebra level have been used both in cattle and sheep because this position can be clearly identified and such measurements are valuable for evaluating carcass quality (McEwan et al., 1989; Young and Deaker, 1994; Suguisawa, 2002) or predicting the quantity of chemical fat in the empty body of sows (King et al., 1986; Dourmad et al., 1997). However, the correlations between ultrasound measurements at the 13 th thoracic vertebra and carcass fat have quite often been poorer than those obtained in our study. In an earlier report, Leymaster et al. (1985), using a Scanogram with a 2-MHz probe, found that the correlation between predicted and observed chemical composition of sheep was less than 0.6 using the independent variable above mentioned. McEwan et al. (1989), using a 3-MHz probe, and Young and Deaker (1994), using a 5-MHz probe and the same equipment (Aloka 210DX), reported coefficients of determination of 0.64 and 0.58 , respectively, for the relationship between ultrasound measurements at the 13th thoracic vertebra and carcass fat. The better results we achieved can be explained by the utilization of a highfrequency probe $(7.5 \mathrm{MHz})$ and by the improved image resolution $(0.2 \mathrm{~mm})$, which is capable of detecting differences in s.c. fat depth between animals that characteristically have low values for this trait, as is the case with sheep. As reported by Young et al. (1992), s.c. fat depth has improved repeatability when an image analysis sys- tem is used rather than measurements made directly from ultrasound monitors, which is explained by the small size of the monitors and the low resolution of the measurements $( \pm 1 \mathrm{~mm})$ compared with those of the image analysis system $( \pm 0.1 \mathrm{~mm})$.

On the whole, the prediction of body chemical composition obtained in this study from single traits measured in live animals is better than others previously reported in sheep and discussed earlier in this article. Although it is well known that differences in an operator's expertise may contribute greatly to the variation of measurements in cattle, sheep, and pigs (McLaren et al., 1991), advances in the ultrasound technology used here have contributed to the improvements observed in this study.

\section{Estimates of Chemical Composition and Energy Value of Empty Body and Carcass from Ultrasound Measurements and Body Weight \\ by Multiple Regression}

Because the principal determinant of the composition of gains made by growing animals, and hence of the chemical composition and the energy value of the whole body or carcass, is their BW (Reid, 1968), this independent variable was tested both alone and with ultrasound measurements in multiple regression equations to assess the extent of improvement that could be achieved in prediction accuracy. Table 5 shows the best equations obtained.

Apart from the prediction of the amount and proportion of protein in the empty body and carcass, the simul- 


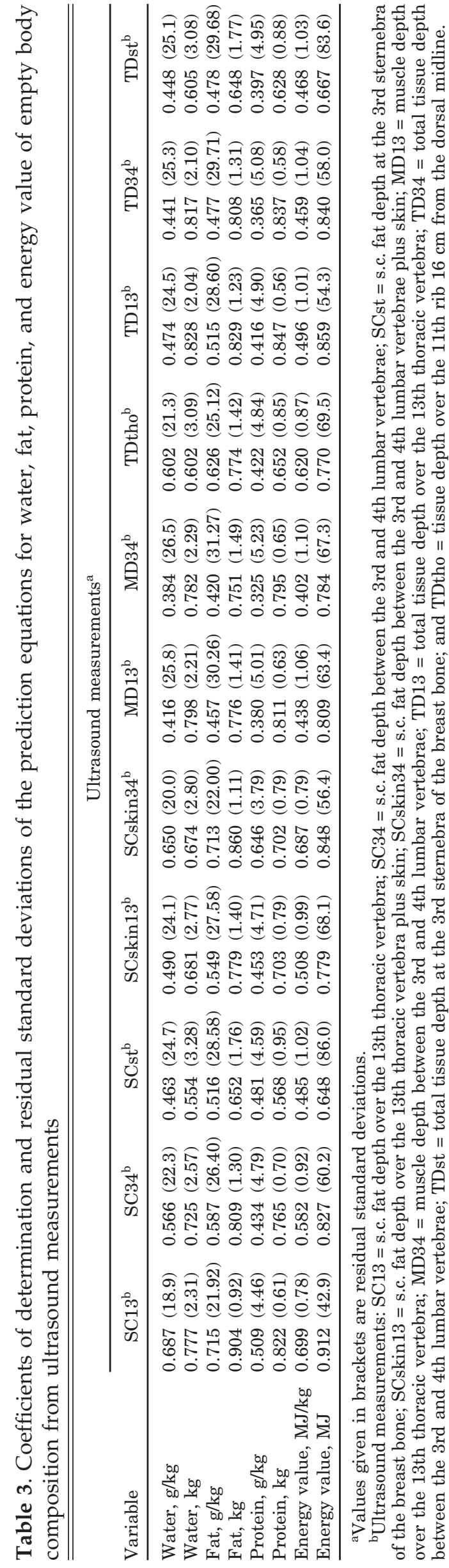

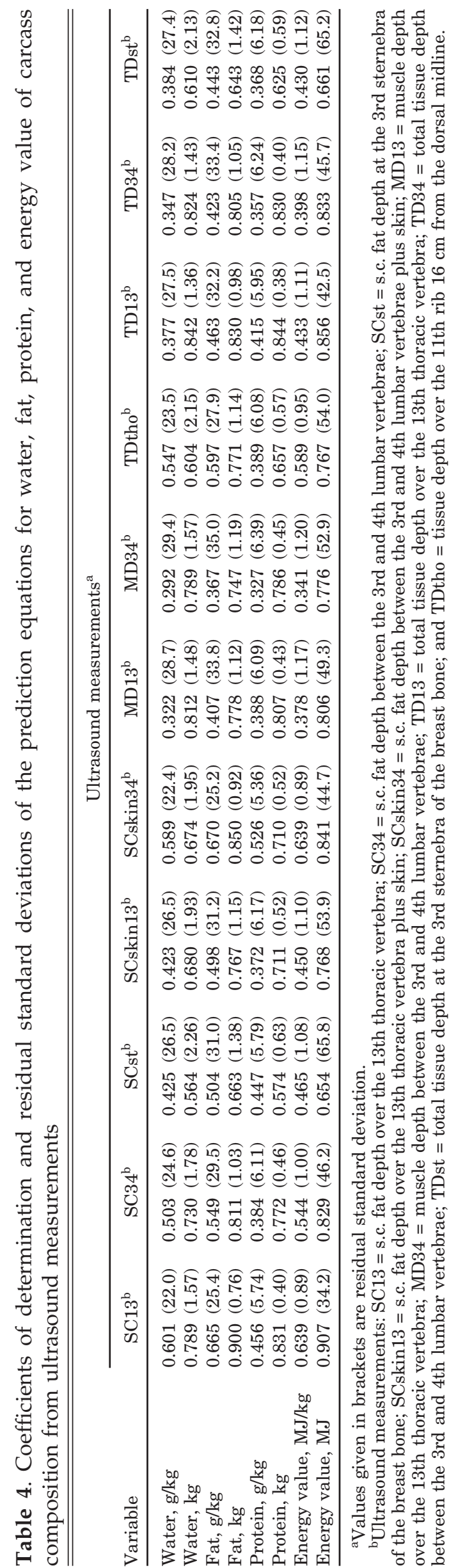


Table 5. Coefficients $( \pm \mathrm{SE}$ ) for equations accounting for the highest significant improvement of fit in predicting weights of water, fat, protein, and their proportions and energy value of empty body and carcass

\begin{tabular}{|c|c|c|c|c|c|c|c|c|}
\hline Item & BW & $\mathrm{SC} 13^{\mathrm{a}}$ & SCskin $34^{\mathrm{a}}$ & TDtho $^{\mathrm{a}}$ & Constant & $\mathrm{Cp}^{\mathrm{a}}$ & $\mathrm{R}^{2}$ & $\mathrm{rsd}^{\mathrm{a}}$ \\
\hline \multicolumn{9}{|l|}{ Empty body } \\
\hline Water, kg & $0.48 \pm 0.02$ & $0.68 \pm 0.30$ & $-0.90 \pm 0.22$ & & $4.14 \pm 0.66$ & 0.33 & 0.987 & 0.58 \\
\hline Fat, kg & $0.09 \pm 0.03$ & $1.13 \pm 0.29$ & & $0.16 \pm 0.06$ & $-2.79 \pm 0.49$ & 21.9 & 0.947 & 0.71 \\
\hline Fat, g/kg & $-2.85 \pm 0.64$ & $23.6 \pm 8.76$ & $16.5 \pm 6.20$ & $3.36 \pm 1.27$ & $72.0 \pm 19.1$ & 34.5 & 0.861 & 16.15 \\
\hline Protein, kg & $0.13 \pm 0.004$ & & & & $0.45 \pm 0.14$ & 24.7 & 0.975 & 0.23 \\
\hline Energy value, MJ/kg & $-0.10 \pm 0.02$ & $0.88 \pm 0.31$ & $0.52 \pm 0.22$ & $0.12 \pm 0.05$ & $7.37 \pm 0.68$ & 21.6 & 0.854 & 0.57 \\
\hline \multicolumn{9}{|l|}{ Carcass } \\
\hline Water, kg & $0.32 \pm 0.02$ & $0.74 \pm 0.27$ & $-0.72 \pm 0.20$ & & $1.54 \pm 0.60$ & 0.86 & 0.978 & 0.52 \\
\hline Water, $\mathrm{g} / \mathrm{kg}$ & $3.06 \pm 0.65$ & $-23.5 \pm 8.82$ & $-12.7 \pm 6.25$ & $-3.26 \pm 1.28$ & $651.9 \pm 19.3$ & 20.3 & 0.805 & 16.26 \\
\hline Fat, kg & $0.08 \pm 0.02$ & $0.83 \pm 0.23$ & & $0.12 \pm 0.04$ & $-2.55 \pm 0.39$ & 23.3 & 0.947 & 0.57 \\
\hline Fat, g/kg & $-3.17 \pm 0.78$ & $23.6 \pm 10.52$ & $18.5 \pm 7.45$ & $3.86 \pm 1.52$ & $101.6 \pm 23.0$ & 36.4 & 0.825 & 19.39 \\
\hline
\end{tabular}

${ }^{\text {a SC13 }}=$ s.c. fat depth over the 13th thoracic vertebra; SCskin34 = s.c. fat depth between the 3rd and 4th lumbar vertebrae plus skin; TDtho = tissue depth over the 11th rib, $16 \mathrm{~cm}$ from the dorsal midline; $\mathrm{Cp}=$ Mallow's statistic; $r$ sd = residual standard deviation .

taneous utilization of some ultrasound measurements in vivo and $\mathrm{BW}$ as independent variables considerably improved the accuracy of predictions. This was particularly noticeable when chemical components or energy value were expressed as proportions, although the coefficients of determination of the equations predicting the absolute amounts always remained higher and accounted for $95 \%$ or more of the variation observed. Wishmeyer et al. (1996) also found that BW improved the prediction of chemical composition of live lambs compared with body geometric measures or electromagnetic scan readings.

As expected from the single linear equations previously obtained, SC13 was the most reliable independent variable from ultrasound measurements; it was included in all but four (quantity and proportion of protein in the empty body and carcass) of the multiple regression equations. Of the 11 original ultrasound measurements, eight of them (SC34, s.c. fat depth at the 3rd stenebra, s.c. fat depth measured with skin at the 13th thoracic vertabra, muscle depth at the longissimus thoracis et lumborum muscle, TD13, TD34, and tissue depth at the 3rd stenebra) could be eliminated because they did not add to the accuracy of predictions of chemical components or energy value. This decreased number of ultrasound measurements in equations is desirable as it makes the models more practical and applicable.

The consequences of fewer ultrasound measurements were investigated. For the quantity of water in the empty body and carcass, the percentage of variance explained fell to 0.3 and $0.6 \%$, respectively, when SCskin34 was removed. Also, for the quantity of fat in the empty body and carcass, TDtho could be eliminated with a negligible reduction of 0.7 and $0.6 \%$, respectively, in the $R^{2}$ value.
Live weight per se was the best predictor of the absolute quantity of protein, accounting for 97.5 and $96.8 \%$ of the variation observed in the empty body and in the carcass, respectively. Taking into account that for the same BW, within a species, sex, and genotype, the variation in the quantity of water and protein is lower or much lower than that of fat, this should be considered as an expected finding. The same did not occur when BW was used to predict fat quantity $\left(\mathrm{r}^{2}=0.771\right.$ and 0.774 for the empty body and carcass, respectively; data not shown). De Campaneere et al. (2000) found that BW was the best estimator of the total amount of protein $(\mathrm{r}=$ 0.99; $\mathrm{CV}=2.9 \%$ ) in Belgian Blue bulls rather than creatinine, either in blood or in urine.

\section{Implications}

The results of this study strongly suggest that body chemical composition and the retained energy of growing lambs can be predicted by body weight and realtime ultrasonography measurements associated with image analysis. Of the ultrasound measurements, the subcutaneous fat depth at the level of the 13th thoracic vertebra was the most powerful estimator. The use of this noninvasive technique provides a valuable tool both for research into nutrition and breeding and for commercial production. In addition, this equipment is portable, robust, relatively inexpensive, and easy to operate. It can be expected that advances in the technology, such as more refined probes, improved resolution, and color imaging capabilities, will expand both research and commercial applications. Further investigation is needed to examine the application of the technique to measure changes in body composition and the energy content of lactating animals or of animals faced with seasonal variations in feed availability. 


\section{Literature Cited}

AFRC. 1993. Energy and protein requirements of ruminants. An Advisory Manual Prepared by the Agricultural and Food Research Council's Technical Committee on Responses to Nutrients. CAB Int., Wallingford, U.K.

AOAC. 1990. Official Methods of Analysis. 14th ed., Assoc. Off. Anal. Chem., Washington, DC.

ASTN. 1988. Total fat extraction in certain food products according to AOAC. Application Short Note. Tecator, Höganäs, Sweden.

Blaxter, K. L., J. L. Clapperton, and A. K. Martin. 1966. The heat of combustion of urine of lambs and cattle in relation to its chemical composition and to diet. Br. J. Nutr. 20:449-460.

Chadwick, J. P., C. M. Yates, and M. G. Owen. 1993. Comparison of four ultrasonic techniques for in vivo estimation of sheep carcass composition. Page 29 in Proc. Winter Mtg. of the Br. Soc. Anim. Prod., Scarborough, U.K.

De Campaneere, S., L. Fiems, J. Vanacker, and C. Boucqué. 2000. Evaluation of urinary creatinine excretion to estimate in vivo body composition of Belgian Blue double-muscle bulls. Ann. Zootech. 49:335-342.

Dinkel, C. A., L. L. Wilson, H. J. Tuma, and J. A. Minyard. 1965. Ratios and percents as measures of carcass traits. J. Anim. Sci. 24:425-429.

Dourmad, J. Y., Y. Étienne, J. Noblet, and D. Canseur. 1997. Prédition de la Composition chimique des truies reproductrices à partir du poids vif et de l'épissure de lard dorsal. J. Rech. Porc. Fr. 29:255-262.

Gomes, M. J. M. 2001. Efficiency of utilisation of fibrous-feeds offered to the native sheep breed Churra da Terra Quente-Supplementation and genotype as sources of variation. Ph.D. Thesis. Univ. of Trás-os-Montes e Alto-Douro, Vila Real, Portugal. (In Portuguese)

King, R. H., E. Speirs, and P. Eckerman. 1986. A note on the estimation of the chemical body composition of sows. Anim. Prod. 43:167-170.

Lawrence, T. L. J., and V. R. Fowler. 2002. Growth of Farm Animals. 2nd ed. Pages 277-319 in Measuring Growth. CAB Int., Wallingford, U.K.

Leymaster, K. A., H. J. Mersmann, and T. G. Jenkins. 1985. Prediction of the chemical composition of sheep by use of ultrasound. J. Anim. Sci. 61:165-172.
MacNeil, M. D. 1983. Choice of a prediction equation and the use of the selected equation in subsequent experimentation. J. Anim. Sci. 57:1328-1336.

McDonald, P., R. A. Edwards, J. F. D. Greenhalgh, and C. A. Morgan. 2002. Animal Nutrition. 6th ed. Prentice Hall, London, U.K.

McEwan, J. C., J. N. Clarke, M. A. Knowler, and M. Wheeler. 1989. Ultrasonic fat depths in Romney lambs and hoggets from lines selected for different production traits. Proc. N.Z. Soc. Anim. Prod. 49:113-119.

McLaren, D. G., J. Novakofski, D. F. Parrett, L. L. Lo, S. D. Singh, K. R. Neumann, and F. M. McKeith. 1991. A study of operator effects on ultrasonic measurements of fat and longissimus muscle area in cattle, sheep and pigs. J. Anim. Sci. 69:54-66.

Moeller, S. J. 2002. Evolution and use of ultrasonic technology in the swine industry. J. Anim. Sci. 80(Suppl. 2):E19-E27.

Ramsey, C. B., A. H. Kirton, B. Hogg, and J. L. Dobbie. 1991. Ultrasonics, needle and carcass measurements for predicting chemical composition of lamb carcasses. J. Anim. Sci. 69:3655-3664.

Reid, J. T. 1968. Body composition in animals and man. Publication No. 1598. NRC, Washington, DC.

Suguisawa, L. 2002. Ultrasonography as a predicting tool for carcass traits and composition of steers. M.S. Thesis. Escola Superior de Agricultura Luiz de Queiroz, Piracicaba, Brasil.

Szabo, C., L. Babinszky, M. W. A. Verstegen, O. Vangen, A. J. M. Jansman, and E. Kanis. 1999. The application of digital imaging techniques in the in vivo estimation of body composition of pigs: a review. Livest. Prod. Sci. 60:1-11.

Williams, A. R. 2002. Ultrasound applications in beef cattle carcass research and management. J. Anim. Sci. 80(Suppl. 2):E183E188.

Wilson, D. E., 1992. Application of ultrasound for genetic improvement. J. Anim. Sci. 70:973-983.

Wishmeyer, D. L., G. D. Snowder, D. H. Clark, and N. E. Cockett. 1996. Prediction of live lamb chemical composition utilizing electromagnetic scanning (ToBEC). J. Anim. Sci. 74:1864-1872.

Wright, I. A., and A. J. F. Russel. 1984. Estimation in vivo of the chemical composition of bodies of mature cows. Anim. Prod. 38:33-44.

Young, M. J., and J. M. Deaker. 1994. Ultrasound measurements predict estimated adipose and muscle weights better than carcass measurements. Proc. N.Z. Soc. Anim. Prod. 54:215-217.

Young, M. J., J. M. Deaker, and C. M. Jogan. 1992. Factors affecting repeatability of tissue depth determination by real-time ultrasound in sheep. Proc. N. Z. Soc. Anim. Prod. 52:37-39. 